\title{
Comparison of enzyme-linked immunosorbent assay and haemagglutination inhibition test for the detection of Newcastle disease virus antibodies in human sera
}

\author{
S CHARAN, A RAI, AND VM MAHAJAN \\ From the Ocular Microbiology Section of Dr Rajendra Prasad Centre for Ophthalmic Sciences, \\ All India Institute of Medical Sciences, New Dehli-110029, India
}

SUMMARY A comparison of haemagglutination inhibition (HI) and enzyme-linked immunosorbent assay (ELISA) techniques for the detection of antibodies against Newcastle disease virus in sera from persons working in poultry farms and veterinary vaccine institutes and from the general population revealed that $22 \%$ more sera were positive by ELISA compared to HI. No samples were negative by ELISA but positive by HI. While HI titres of positive sera were found in the range 8-64, ELISA titres were between 16 and 512. It was interesting that though $78 \%$ sera had concordant results by the two tests, titres obtained by ELISA were nearly six times higher than those by $\mathrm{HI}$.

Newcastle disease is primarily an infection of chickens and turkeys. In man it has been recognised chiefly as an acute and transient conjunctivitis with preauricular adenitis, fever, and chills. Generalisation of the infection with the presence of virus in blood, urine, and respiratory secretions has been encountered. Owing to frequent outbreaks of this disease in poultry farms and the extensive use of live vaccine, persons engaged in poultry farming and vaccine production units have been constantly at a much higher risk compared to the general population.

To study the prevalence of Newcastle disease virus (NDV) antibodies in the human population, neutralisation and haemagglutination inhibition (HI) tests have been used as serological tools. ${ }^{1-3}$ Owing to the presence of non-specific neutralising substances and antihaemagglutinins against NDV in human sera, the formerly used procedures require some modifications. The conflicting results obtained by these tests ${ }^{4}$ demanded that a more sensitive and specific test be used. We compared HI and enzymelinked immunosorbent assay (ELISA) tests for the detection of NDV antibodies in human sera. Previously, ELISA had been used for NDV antibodies only in chicken sera. ${ }^{5}$

Accepted for publication 13 August 1980

\section{Material and methods}

AN TIGEN

Chick embryos of 9-11 days were inoculated into the allantoic cavity with F strain of NDV obtained from the Veterinary Vaccine Institute, Hissar (Haryana). After 72 hours' incubation, embryos were chilled and the allantoic fluid was pooled. The haemagglutination (HA) titre of the pooled allantoic fluid antigen was found to be 1024 using $0.5 \%$ chick erythrocytes.

SERA

A total of 213 human sera were tested for NDV antibodies, of which 104 were from subjects working in poultry farms and veterinary and vaccine institutes. The remaining 109 samples were obtained from the 0 Clinical Chemistry Laboratory, New Delhi, and N served as controls representing the normal population. All the sera were stored at $-70^{\circ} \mathrm{C}$ till used.

\section{HI TECHNIQUE}

Non-specific reactions of NDV haemagglutination were removed by heat inactivation and kaolin treatment of the sera. ${ }^{3}$ A serum-antigen (4 HAU) mixture was incubated at $37^{\circ} \mathrm{C}$ for 1 hour before the addition of chick red blood cells. Appropriate controls were included during the procedure. 
ELISA TECHNIQUE

This was the modified micromethod of Voller and coworkers. ${ }^{6}$ Polystyrene plates (Microtitre M 29 AR, Dynatech Laboratories, Sussex) were coated with $200 \mu$ l of optimally diluted NDV antigen in $0.06 \mathrm{M}$ carbonate-bicarbonate buffer, $\mathrm{pH} 9 \cdot 6$, after overnight incubation at $4^{\circ} \mathrm{C}$. The plates were washed three

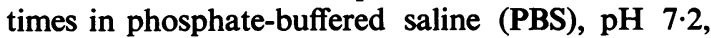
containing $0.05 \%$ Tween-20 (PBS/T). Twofold serial dilutions of the test sera were made, and $200 \mu \mathrm{l}$ was added to each well of the plate in vertical rows, except the last row which was left as an antigen control. The plates were incubated at $37^{\circ} \mathrm{C}$ for 1 hour and washed three times conventionally with PBS/T; $200 \mu$ l amounts of $1: 8000$ diluted anti-human IgG-peroxidase conjugate (Miles Laboratories, Slough, UK) were added to each well. Again the plates were incubated at $37^{\circ} \mathrm{C}$ for 1 hour. After further washing, $o$-phenylenediamine substrate (40 $\mathrm{mg} / 100 \mathrm{ml}$ phosphate-citrate buffer, pH 5.0 , with $40 \mu \mathrm{l}$ of $30 \% \mathrm{H}_{2} \mathrm{O}_{2}$ ) was added in equal amounts of $200 \mu \mathrm{l}$ to each well, and the reaction was allowed to proceed at room temperature for $20 \pm 5$ minutes. The reaction was stopped by adding $50 \mu l$ of $5 N$ $\mathrm{H}_{2} \mathrm{SO}_{4}$ to each well. Results were recorded on the basis of the intensity of colour developed.

\section{Results}

Of the total 213 sera, $167(78 \%$ ) gave concordant results, $44(20 \%)$ being positive and $123(58 \%)$ negative for NDV antibodies by both tests. Forty-six $(22 \%)$ sera were found to be positive by ELISA but were negative by $\mathrm{HI}$ test. Of these 46 sera, 43 belonged to the high-risk population while only three were from the general population category. No serum was negative by ELISA but positive by HI (Table 1 and Figure).

The correlation between ELISA and $\mathrm{HI}$ titres among the high-risk population is shown in Table 2.

Table 1 Comparison of ELISA and HI tests for detection of NDV antibodies in high-risk population and general population

\begin{tabular}{lccccc}
\hline Type of population & \multicolumn{2}{c}{ Serum samples } & & \multicolumn{2}{c}{ NDV antibody by: } \\
\cline { 2 - 3 } & Number & $\%$ & & ELISA & $H I$ \\
\hline High-risk 104 Sera & 40 & 39 & + & + \\
& 21 & 20 & & - & - \\
General 109 Sera & 43 & 41 & & + & - \\
& 102 & $93 \cdot 5$ & & - & - \\
Combined 213 Sera & 4 & $3 \cdot 7$ & & + & + \\
& 44 & $2 \cdot 8$ & & + & - \\
& 123 & 20 & & + & - \\
& 46 & 22 & & + & - \\
\hline
\end{tabular}

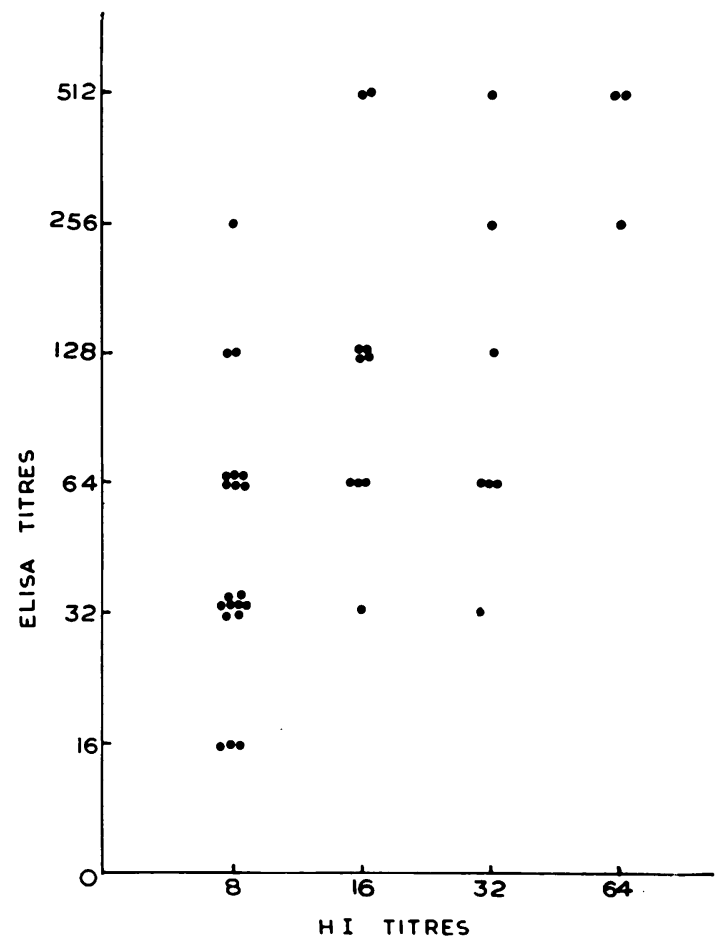

Comparison of antibody titres measured by $\mathrm{HI}$ and ELISA in 40 human sera positive by the two tests.

Table 2 Correlation of corresponding HI titres of NDV antibodies with that of ELISA in 104 sera from high-risk population

\begin{tabular}{cccccc}
\hline HI titre & \multicolumn{3}{l}{ Number of sera with } & ELISA titres: & Total \\
\cline { 2 - 5 } & $<16$ & $16-32$ & $64-128$ & $256-512$ & \\
\hline$<8$ & 21 & 33 & 8 & 2 & 64 \\
8 & 0 & 11 & 8 & 1 & 20 \\
16 & 0 & 1 & 7 & 2 & 10 \\
32 & 0 & 1 & 4 & 2 & 7 \\
64 & 0 & 0 & 0 & 3 & 3 \\
Total & 21 & 46 & 27 & 10 & 104 \\
\hline
\end{tabular}

ELISA titres of the 64 sera that were negative by HI were in the range $<16-512 ; 21$ sera had titres $<16$; 33 sera had titres of $16-32$; while the remaining 10 sera had titres of $64-512$. Moreover, of the 67 sera that had ELISA titres of up to only 32,54 were negative by $\mathrm{HI}, 11$ had $\mathrm{HI}$ titres of 8 , and the remaining two were HI positive with titres of 16 and 32, respectively.

\section{Discussion}

The ELISA technique has been applied and compared 
with other conventional tests in various conditions as a diagnostic and surveillance tool. ${ }^{7}$ By virtue of its sensitivity, specificity, and other advantages, it safely gets recommendations even for routine purposes. Earlier it had been used in studies on NDV infection in chickens. In our studies also, ELISA has been shown to be far more sensitive than HI. Only $20 \%$ of a total of 213 sera from a mixed population were positive for NDV antibodies by $\mathrm{HI}$ $39 \%$ from a high-risk population and $4 \%$ from the general population) with titres ranging between 8 and 64 . ELISA could detect antibodies in $42 \%$ of sera (80\% from a high-risk population and $7 \%$ in the general population) with titres up to 512 . The additional advantage of ELISA over $\mathrm{HI}$ is that, while screening for NDV antibodies, the occurrence of non-specific antihaemagglutinin and inhibitors is not important. The confusion regarding its antigenic relation to mumps virus is overcome due to its high specificity. Since $\mathrm{HI}$ antibodies and neutralising antibodies are the functions of different components on the surface of the virus (haemagglutinin and neuraminidase receptors), the pattern of the two antibodies does not need to be parallel. The tests detecting either type of antibody will be a misrepresentation of the facts. Hence, the lack of correlation between HI and neutralising antibodies encountered by many workers ${ }^{1348}$ can easily be answered. Because ELISA can detect both types of antibodies against NDV, a high positivity of sera by this technique can be justified. No serum sample was negative by ELISA but positive by the HI test.

Both the tests had $78 \%$ concordant results, and sera positive by the two tests have shown a good correlation in their titres. By ELISA, $22 \%$ more sera were positive than by $\mathrm{HI}$, of which $41 \%$ sera were from a high-risk population and only $3 \%$ from the general population, indicating that high positivity by ELISA was due to detection of the lowest levels of antibodies rather than to false-positive indications. On an average the titres obtained by ELISA were six times higher than by HI.

\section{References}

${ }^{1}$ Evans AS. Newcastle disease neutralizing antibody in $\vec{\circ}$ human sera and its relationship to mumps virus. $A m J$ Hygiene 1954;60:204-13.

${ }^{2}$ Hsiung GD, Isacson $P$, Tucker G. Studies on parainfluenza virus. 2. Serological inter-relationship in humans. Yale $J \overrightarrow{\widehat{0}}$ Biol Med 1963;35:534-44.

${ }^{3}$ Miller LT, Yates VJ. Reaction of human sera to avian adenoviruses and Newcastle disease virus. Avian Dis: $1971 ; 15: 781-8$.

4 Zhdanov V, Bukrinskaya A. Further considerations on nomenclature of parainfluenza viruses. Virology 1960;10: 음 146-9.

${ }^{5}$ Voller A, Bidwell DE, Bartlett A. Microplate ELISA in virology. Biomedical Applications of Immobilized Enzymes and Proteins, Vol. 2. Ed Chang T. Plenum Press, 1977; 119-28.

${ }^{6}$ Voller A, Bidwell DE, Bartlett A. Microplate ELISA for the immunodiagnosis of virus infections. Chapter 69 in $\vec{\bullet}$ Manual of Clinical Immunology. Eds, Rose N, Friedman $\infty$ H. American Society of Microbiology, 1976; 506-12.

7 Voller A, Bartlett A, Bidwell DE. Enzyme immunoassays with special reference to ELISA techniques. J Clin Pathol 1978;31:507-20.

${ }^{8}$ Dardiri AH, Yates VJ, Flanagan TD. The reaction to infection with B1 strain of Newcastle disease virus in man. Am J Vet Res 1962;23:918-20.

Requests for reprints to: Dr VM Mahajan, Ocular Microbiology Section, Dr Rajendra Prasad Centre for Ophthalmic Sciences, All India Institute of Medical Sciences, Ansari Nagar, New Delhi-110029, India. 